\title{
$\mathrm{Csl}: \mathrm{Gd}$ 결정 육성과 섬광 특성
}

\author{
천종규 $1 \cdot$ 김성환 $2,+\cdot$ 김홍주 3
}

\section{Crystal Growth and Scintillation Properties of CsI:Gd}

\author{
Jong-Kyu Cheon', Sunghwan Kim²,+, and Hong-Joo Kim³
}

\begin{abstract}
CsI:Gd crystal was grown by the Bridgeman method and its scintillation properties were investigated. The wavelength peak of the luminescence spectrum for the crystal excited by X-ray was $419 \mathrm{~nm}$. The range of the spectrum was from $300 \mathrm{~nm}$ to $800 \mathrm{~nm}$. The spectrum well matched to the quantum efficiency of a typical bi-alkali photo-multiplier tube(PMT). An energy resolution of $48.2 \%$ was obtained for $662 \mathrm{keV} \gamma$-rays of ${ }^{137} \mathrm{Cs}$. The three decay times were obtained as a fast( $(557.4 \mathrm{~ns}, 42.2 \%)$, intermediate $(1.78 \mu \mathrm{s}, 29.7 \%)$ and slow $(5.43 \mu \mathrm{s}, 28.1 \%)$ components, respectively.
\end{abstract}

Keywords : Bridgman method, CsI : Gd, CsI, scintillator, crystal growth

\section{1. 서 론}

방사선 섬광체 검출기는 반도체검출기에 비하여 에너지분해능이 나쁘지만, 유효원자번호가 높고 검출기의 크기를 비교적 크게 만들 수 있다. 이 때문에 섬광검출기는 고에너지 방사선의 검출 효율이 높아서 의료영상장치, 고에너지물리실험, 보안검색장치 등에 널리 사용되고 있다[1-3].

$\mathrm{CsI}$ 섬광체는 기계적 강도가 우수하고, 흡습성이 적으며, Tl이나 $\mathrm{Na}$ 를 활성제로 첨가한 $\mathrm{CsI}$ 섬광체는 광출력이 높아서 50여 년간 계측장치의 여러 분야에서 채택되고 있을 만큼 신뢰도와 안정성이 높은 섬광체이다. CsI에 첨가되는 활성제에 따라 섬광특성이 달라 지는 데 순수한 $\mathrm{CsI}$ 는 광출력이 낮은 대신 형광감쇠시간이 짧다. 또 $\mathrm{Tl}$ 을 첨가한 것은 광출력이 높아서 많이 사용되고 있으며 $\mathrm{Na}$ 를 첨 가한 것은 광출력도 높고 발광중심파장이 광전자증배관(photomultiplier tube, PMT )과 정합되는 특성이 있다[4-7].

본 연구에서 $\mathrm{CsI}$ 섬광물질에 $\mathrm{Gd}$ 를 첨가하여 새로운 섬광물질인 $\mathrm{CsI}: G d$ 를 개발하였다. 브리지만 법으로 CsI:Gd 섬광결정을 육성하 고 방사선센서로서 활용가능 여부를 조사하기 위하여 CsI:Gd의

1서라벌대학교 방사선과(Radiologic Technology, Sorabol College) 2청주대학교 방사선학과(Department of Radiological Science, Cheongju Unversity)

3경북대학교 물리학과(Department of Physics, Kyungpook National Unversity)

+Corresponding author: kimsh@cju.ac.kr

(Received : May 23, 2012, Accepted : Jul. 3, 2012)
$\mathrm{X}$-선 발광특성과 에너지분해능, 형광감쇠특성 등을 평가하였다.

\section{2. 실험 방법}

\section{$2.1 \mathrm{Cs} \mid: G d$ 결정 육성과 시편제작}

본 연구에서는 수직형 브릿지만 장치를 이용하여 $\mathrm{CsI}: \mathrm{Gd}$ 를 육 성하였다. CsI(Aldrich $99.9 \%$ )와 0.5 mole\% $\mathrm{GdI}_{3}$ (Aldrich 99.9 $\%$ )를 정량하여, 내경 $10 \mathrm{~mm}$ 의 석영관에 넣고 고진공상태에서 밀 봉하여 브릿지만 단결정 성장용 앰플을 만들었다. 석영앰플 내의 고 진공상태를 유지하는 것은 첫째, 시약이 공기와 접촉하여 산화되는 것을 방지하고, 둘째, 공기 중의 불순물이 단결정에 첨가되는 것을 방지하며 셋째, 결정성장 시 앰플 내의 증기압에 의한 앰플 파손을 막을 수 있기 때문이다. 앰플 내부를 고진공상태로 만들기 위해 오 일확산펌프를 사용하였으며, 이때 앰플 내의 진공도는 10-6 Torr 이었다.

본 연구에 사용된 브릿지만 결정성장 장치는 2 개의 전기로 영역 으로 구성되어 결정성장 온도의 기울기를 조절할 수 있도록 설계되 었다. 결정 육성 시 상부전기로는 $700{ }^{\circ} \mathrm{C}$, 하부전기로는 $450{ }^{\circ} \mathrm{C}$ 로 설정하여, 단결정 성장지점에서의 온도기울기를 $8{ }^{\circ} \mathrm{C} / \mathrm{cm}$ 로 설정 하였다. 시약앰플을 $0.5 \mathrm{~mm} / \mathrm{h}$ 의 속도로 원통형 전기로 내부에 하 강시킴으로써 결정을 육성하였다. 육성을 마친 앰플은 열적인 스트 레스에 의한 결정의 균열을 막기 위하여 15 시간에 걸쳐 서서히 상온 
까지 온도를 낮추었다.

육성된 결정은 절단과 표면연마를 통하여 실험에 사용 가능하도 록 가공하였다. 결정의 절단과정에서 물리적 충격으로 인한 결정의 균열을 방지하기 위하여 다이아몬드 와이어 커터를 이용하여 서서 히 절단하였다. 난반사를 줄이고 광투과율을 높이기 위해 절단된 면 은 $\mathrm{Al}_{2} \mathrm{O}_{3}$ 분말(Buehler, No. 40-6301-016)로 연마하였으며, 방사 선에 의해 발생된 광 손실을 최소화하고 광 집속량을 높이기 위하여 반사체로서 테프론 테이프를 결정 시편에 주위에 밀착하여 감았다. Fig. 1은 본 연구에서 육성한 직경 $10 \mathrm{~mm}$, 길이 $10 \mathrm{~mm}$ 인 CsI:Gd 단결정 섬광체의 사진이다. 육성된 $\mathrm{CsI}: \mathrm{Gd}$ 단결정의 결정구조는 공 간그룹 Pm3m의 체심입방구조(bcc; body centered cubic)이다.
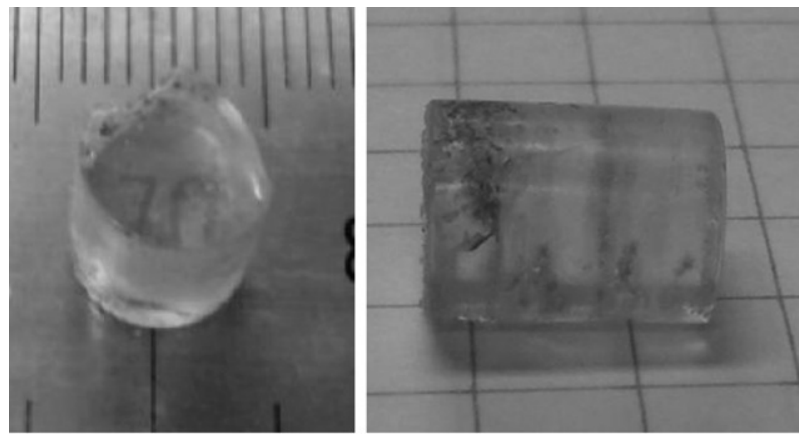

Fig. 1. The sample of CsI:Gd scintillation crystal.

\section{$2.2 \mathrm{X}$-선 섬광스펙트럼 실험 장치}

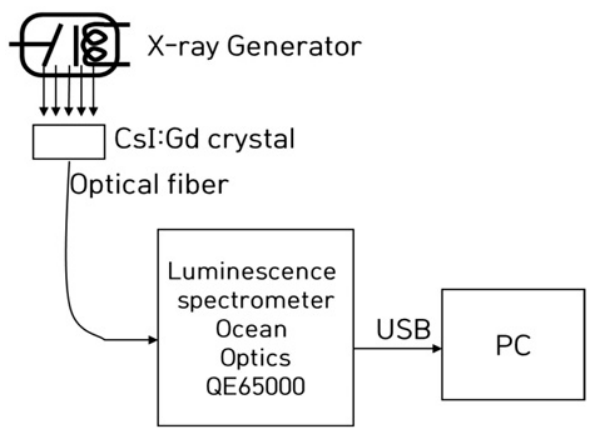

Fig. 2. X-ray luminescence spectrum measurement system.

제작된 시편에 대하여 $\mathrm{CsI}: \mathrm{Gd}$ 의 X-선 섬광스펙트럼을 측정하였 다. 섬광체는 반드시 광전자증배관 또는 포토다이오드와 같은 광센 서와 결합하여야 방사선에 의한 섬광을 전기적 신호로 변환시킬 수 있다. 그러므로 섬광체의 발광 파장범위와 중심파장이 광센서의 양 자효율이 높은 파장범위와 정합하는 지 여부는 광센서를 선택하는 데 중요한 정보가 된다. Fig. 2는 X-선 섬광 스펙트럼을 측정하기 위한 시스템의 개략도이다. 본 시스템에서는 섬광체를 여기시키기 위한 X-선 발생장치(DR-GEM)와 X-선 형광분석을 하는 포토스 펙트로미터(QE65000 spectrometer, Ocean Optics), X-선 형광
을 포토스펙트로미터로 전달하는 광섬유 연결선으로 구성된다.

\section{3 에너지스펙트럼, 형광감쇠시간 측정용 실험 장치}

${ }^{137} \mathrm{Cs}$ 감마선원을 이용하여 $\mathrm{CsI}: \mathrm{Gd}$ 의 에너지스펙트럼과 형광감 쇠시간특성을 측정하였다. Fig. 3 은 감마선 에너지 스펙트럼 측정 시스템을 나타낸다. 섬광검출기에서 발생되는 신호의 크기는 곧 방 사선의 에너지에 비례한다. 그러므로 신호 파고스펙트럼은 곧 에너 지스펙트럼을 의미하며 이를 분석함으로써 그 검출기의 에너지분해 능을 파악할 수 있다. 형광감쇠시간은 곧 검출기의 불감시간에 비례 하며, 높은 조사선량률을 나타내는 환경에서 사용가능하기 위해서 는 형광감쇠시간이 짧은 섬광검출기를 사용할수록 유리하다. 에너 지스펙트럼 측정장치는 $662 \mathrm{keV}$ 의 감마선을 발생하는 ${ }^{137} \mathrm{Cs}$ 선원, 섬광을 전기적 신호로 바꾸는 광전자증배관(Photonis, XP2260), 광전자증배관을 구동시키기 위한 고압전원공급장치, 광전자증배관 의 신호를 증폭하는 선형증폭기(Ortec 570), 증폭된 아날로그신호 를 디지털로 변환하는 $25 \mathrm{MHz}$ 플레시 $\mathrm{AD}$ 변환기(Notice $\mathrm{FADC} 25)$ 와 $\mathrm{AD}$ 변환기를 제어하고 변환한 신호를 저장하는 컴퓨 터로 구성된다. 본 연구에서 실험데이터의 상대오차를 $1 \%$ 로 만들 기 위하여 10,000 개 이상의 신호를 측정하도록 설정하였다. 측정장 치에서 발생된 신호의 파형은 그대로 $\mathrm{PC}$ 에 저장되며 리눅스기반의 $\mathrm{ROOT}$ 응용 프로그램[8]으로 $\mathrm{AD}$ 변환기의 데이터를 실시간으로 컴퓨터에 저장한다. 저장된 원시데이터는 ROOT 프로그램의 기본 명령어 조작으로 히스토그램의 한 형태인 에너지스펙트럼으로 변환 하고 가우시안 피팅 과정을 통하여 에너지분해능을 산출하였다.

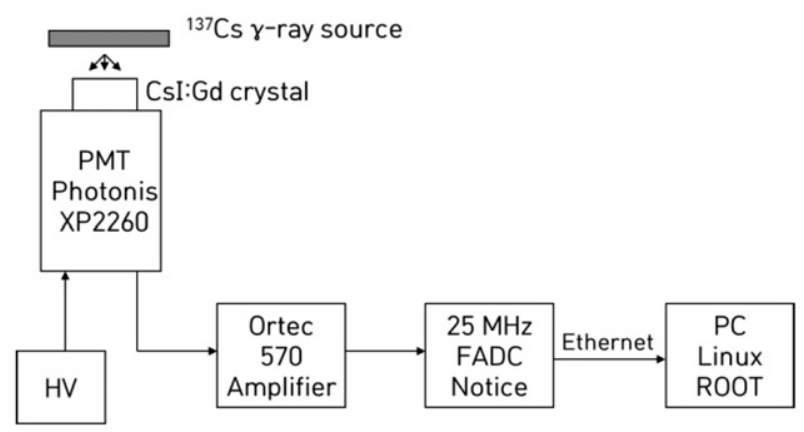

Fig. 3. $\gamma$-ray energy spectrum measurement system.

Fig. 4는 형광감쇠시간 측정용 시스템의 개념도이다. 형광감쇠시 간 측정용 장치는 감마선원, 광전자증배관, 고압전원공급장치, 400 $\mathrm{MHz} \mathrm{AD}$ 변환기와 컴퓨터로 구성된다. 섬광체에서 발생되는 빠른 신호의 형광감쇠시간을 측정하기 위해 선형증폭기를 거치지 않고 약간 높은 PMT 전압을 인가한 High gain 모드로 $\mathrm{AD}$ 변환기에서 광전자증배관의 신호를 직접 수집한다. 측정된 10,000 개의 신호는 역시 리눅스 응용프로그램을 이용하여 peak 위치를 기준으로 모두 합산을 하여 시간 대 형광감쇠특성그래프를 그린다. 이 그래프를 지 
수함수 피팅을 하여 형광감쇠시간을 산출하였다.

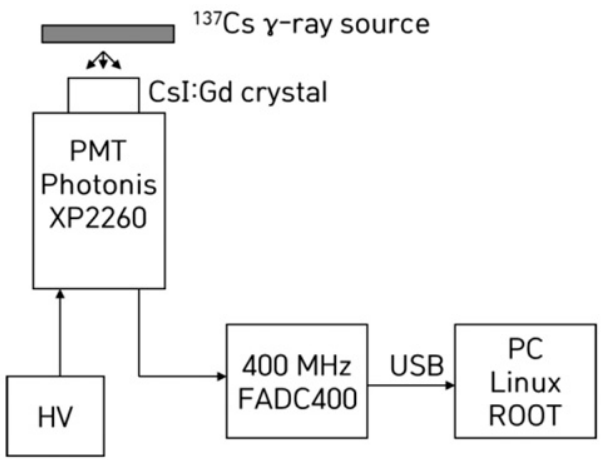

Fig. 4. Scintillation decay time measurement system.

\section{3. 결과 및 고찰}

\section{$3.1 \mathrm{X}$-선 섬광스펙트럼}

Fig. 5는 CsI:Gd의 X-선 섬광스펙트럼을 보여준다. X선 발생장 치의 관전압은 $82 \mathrm{kV}$, 관전류는 $1 \mathrm{~mA}$ 이었고, 포토스펙트로미터 의 노출시간은 30 초이었다. X-선 섬광스펙트럼의 중심파장은 419 $\mathrm{nm}$ 이었으며, 발광파장범위는 $300 \mathrm{~nm} \sim 800 \mathrm{~nm}$ 이었다.

순수한 $\mathrm{CsI}$ 의 중심파장은 $315 \mathrm{~nm}$ 인데 $\mathrm{Na}^{+}$불순물 이온이 첨가 되면 발광파장은 $410 \mathrm{~nm}$ 가 되고 $\mathrm{Tl}+$ 이 첨가되면 $550 \mathrm{~nm}$ 로 변화 된다 $[9,10]$. 첨가된 불순물 이온이 발광중심이 되며 이온의 천이과 정에 의하여 섬광스펙트럼의 파장이 결정된다. 이와 같은 작용으로 $\mathrm{CsI}$ 내에 $\mathrm{Gd}^{3+}$ 불순물 이온의 첨가에 의해서 중심파장이 $419 \mathrm{~nm}$ 로 변화된 것으로 판단된다. 본 실험에서 사용된 바이알칼리 광전자 증배관 Photonis XP2260의 광감수성 범위는 $350 \mathrm{~nm} \sim 500 \mathrm{~nm}$ [11]이며, $\mathrm{CsI}: \mathrm{Gd}$ 의 섬광스펙트럼 파장범위와 잘 일치되므로 광손 실은 줄이고, 검출효율 높일 수 있다.

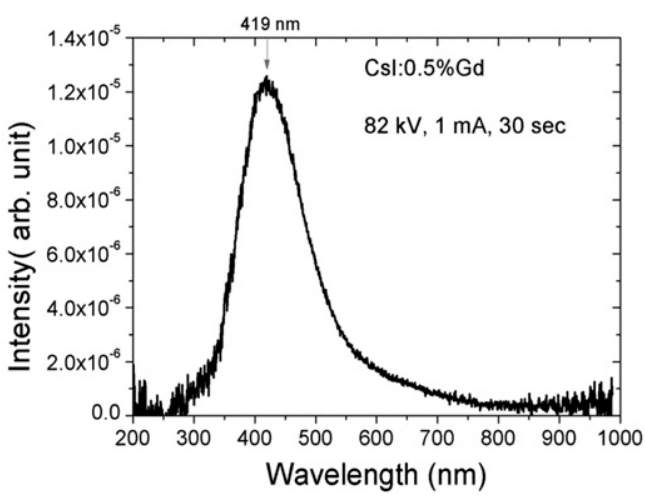

Fig. 5. X-ray luminescence spectrum of CsI : Gd.

Fig. 6은 $\mathrm{CsI}$ 내에서 $\mathrm{Gd}^{3+}$ 이온의 에너지 준위를 보여주며 $\mathrm{Gd}^{3+}$
이온의 발광과정은 ${ }^{6} \mathrm{P}_{7 / 2} \rightarrow{ }^{8} \mathrm{~S}_{7 / 2}$ 천이과정에 의한다. ${ }^{6} \mathrm{D}$ 와 ${ }^{6}$ 로부 터의 천이는 금지되어있다. 여기서 Wavenumber는 섬광 파장의 역수로서 에너지에 비례하는 값을 의미하며, ${ }^{6} \mathrm{P}_{7 / 2} \rightarrow{ }^{8} \mathrm{~S}_{7 / 2}$ 천이과 정의 wavenumber는 약 $24 \times 10^{3} \mathrm{~cm}^{-1}$ 이며 이는 발광파장으로 $419 \mathrm{~nm}$ 에 해당한다[12].

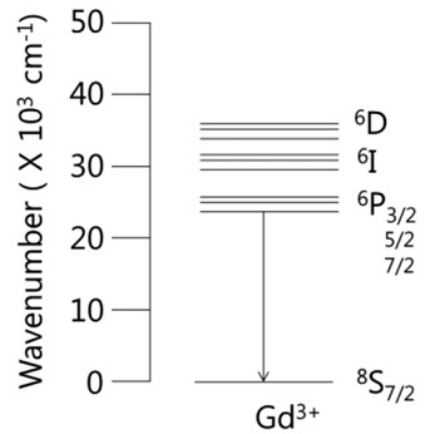

Fig. 6. Energy level diagram of $\mathrm{Gd}^{3+}$ in cesium iodide

\section{2 에너지 스펙트럼}

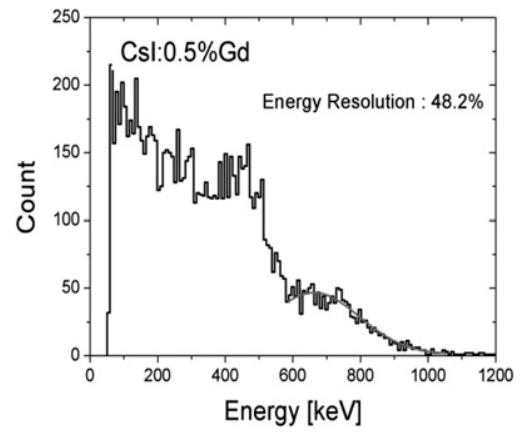

Fig. 7. Energy spectrum of CsI:Gd excited by $662 \mathrm{keV} \gamma$-rays.

Fig. 7은 ${ }^{137} \mathrm{Cs}$ 의 $662 \mathrm{keV}$ 감마선에 대한 $\mathrm{CsI}: \mathrm{Gd}$ 의 에너지스펙 트럼과 분해능을 나타낸다. 본 실험에서 광전자증배관의 인가전압 은 $-1400 \mathrm{~V}$, 선형증폭기의 Gain 은 100 , Shaping time 은 $1 \mu$ 이 었다. 분석한 결과 $\mathrm{CsI}: \mathrm{Gd}$ 의 에너지분해능은 $662 \mathrm{keV}$ 에 대하여 $48.2 \%$ 로 측정되었다.

Fig. 7의 에너지스펙트럼에서 피팅된 피크는 전에너지흡수 피크 로서 $662 \mathrm{keV}$ 의 감마선이 $\mathrm{CsI}: \mathrm{Gd}$ 결정에 모두 흡수된 경우에 나 타난다. 전 에너지흡수 피크보다 낮은 에너지의 스펙트럼은 컴프턴 산란에 의하여 에너지의 일부가 감마선으로 검출기 밖으로 빠져나 가고, 검출기에 흡수된 나머지 에너지의 신호를 나타낸다. 에너지 분해능은 스펙트럼의 전에너지흡수 피크를 가우시안 피팅하여 반치 폭을 산출하고 이 반치폭을 감마선의 에너지로 나눈 퍼센트 비율이 다. 본 연구에서 $\mathrm{CsI}: \mathrm{Gd}$ 의 에너지 분해능은 $662 \mathrm{keV}$ 에 대하여 $48.2 \%$ 로 측정되었다. $\mathrm{CsI}: G d$ 의 에너지 분해능이 타 섬광체에 비 하여 저하된 특성을 보이므로 방사선의 에너지 분석용으로는 사용 
할 수 없으나, 방사선의 에너지 측정없이 계수 또는 계수율 모드로 사용되는 서베이미터나 산업용 두께계 등에 활용이 가능할 것으로 사료된다.

\section{3 형광감쇠 특성}

Fig. 8은 $\mathrm{CsI}: \mathrm{Gd}$ 의 형광감쇠 특성을 보여준다. 본 실험에서 광전 자증배관의 인가전압은 $-1700 \mathrm{~V}$ 이었고 ${ }^{137} \mathrm{Cs}$ 의 $662 \mathrm{keV}$ 감마선 으로 형광감쇠 특성을 조사하였다.

본 연구에서 산출된 $\mathrm{CsI}: \mathrm{Gd}$ 의 섬광감쇠시간과 그 비율로서 빠른 성분은 $557.4 \mathrm{~ns}$ 가 $42 \%$, 중간 성분으로 $1.78 \mu \mathrm{s}$ 가 $29.7 \%$, 느린 성분은 $5.43 \mu \mathrm{s}$ 가 $28.1 \%$ 이었다.

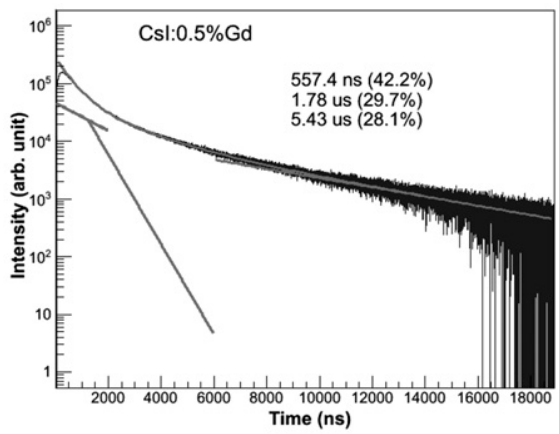

Fig. 8. The fluorescence decay curve of CsI:Gd excited by 662 $\mathrm{keV} \gamma$-rays.

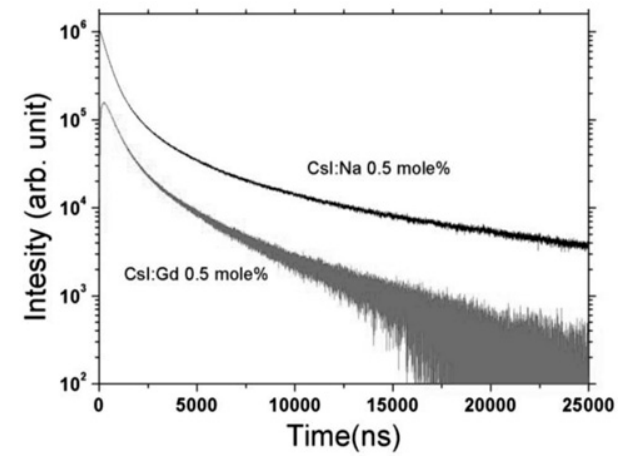

Fig. 9. Comparison of the fluorescence decay curve between CsI:Gd and CsI:Na.

Fig. 9은 CsI:Gd와 CsI:Na의 섬광감쇠곡선을 비교한 그림이다. 기존에 연구된 비슷한 $\mathrm{CsI}$ 계열 섬광체인 $\mathrm{CsI}: \mathrm{Na}$ 의 섬광감쇠시간 은 빠른 성분 $457 \mathrm{~ns}(37 \%)$, 중간 성분 $1.92 \mu \mathrm{s}(31 \%)$, 느린 성분 $10 \mu \mathrm{s}$ (32\%)이었다[4]. CsI:Gd의 섬광감쇠특성은 $\mathrm{CsI}: \mathrm{Na}$ 에 비하여 빠른 성분과 중간 성분은 크게 차이가 없으나 느린 성분의 차이가 약 50 $\%$ 가량 낮은 것으로 나타났다. 느린 성분의 감쇠시간이 높을 경우 고방사선량률 환경에서 신호의 pile-up을 증가시켜서 검출효율을 저하시킨다.

\section{5. 결론}

본 연구에서 브릿지만 방법으로 신소재 $\mathrm{CsI}: \mathrm{Gd}$ 섬광체를 육성하 고 X-선과 감마선에 대한 섬광특성을 조사하였다. X-선 형광의 중 심파장은 $419 \mathrm{~nm}$ 로 일반적인 바이알칼리 광전자증배관과 잘 정합 하였다. 에너지분해능은 $48.2 \%$ 로 일반적인 $\mathrm{CSI}$ 섬광검출기에 비 하여 저하된 특성을 보여주었다. 형광감쇠시간은 $557.4 \mathrm{~ns}(42 \%)$, $1.78 \mu \mathrm{s}(29.7 \%), 5.43 \mu \mathrm{s}(28.1 \%)$ 로 세 가지 성분을 나타내었다. 본 연구를 통하여 $\mathrm{CsI}: \mathrm{Gd}$ 가 에너지 분해능이 좋지 않아 에너지분석용 보다는 계수율 모드의 방사선 검출기로서 활용할 수 있음을 확인하 였으며, 섬광감쇠시간의 느린 성분이 기존 $\mathrm{CsI}: \mathrm{Na}$ 에 비하여 $50 \%$ 로 적어서 고방사선량률 환경에 더욱 유리하다. $\mathrm{Gd}$ 의 대표적인 안 정동위원소인 ${ }^{155} \mathrm{Gd}$ 와 ${ }^{157} \mathrm{Gd}$ 의 열중성자에 대한 산란단면적은 각각 61,000 barn, 255,000 barn 으로 자연계에 존재하는 안정한 핵종 중에서는 중성자 산란단면적이 가장 크기 때문에 중성자 검출기로 서의 활용 가능할 것으로 기대된다.

\section{감사의 글}

이 논문은 2012년도 국토해양부의 U-기반 해운물류 체계구축을 위한 기반기술 연구비에 의하여 연구되었음.

\section{REFERENCES}

[1] M. J. Weber, "Inorganic scintillators : today and tomorrow", J. Lumin., vol. 100, Issues 1-4, pp. 35-45, 2002.

[2] C.L. Melcher, "Perspectives on the future development of new scintillators", Nucl. Instr. Meth., A, vol. 537, Issues 1-2, pp. 6-14, 2005.

[3] J. K. Cheon, S. Kim, G. Rooh, J.H. So, H.J. Kim, and H. Park, "Scintillation characteristics of $\mathrm{Cs}_{2} \mathrm{LiCeBr}_{6}$ crystal", Nucl. Instr. Meth., A, vol. 652, Issues 1, pp. 205-208, 2011.

[4] J. K. Cheon, S. Kim, and H. J. Kim, H. J., "Crystal growth and scintillation properties of CsI:Na", J. Kor. Sensors Soc., vol. 19, no. 6, pp. 443-448, 2010.

[5] G.-J. Gang, S.-H. Doh, W.-G. Lee, and M.-Y. Oh, "Scintillation Characteristics of CsI: $\mathrm{X}\left(\mathrm{X}=\mathrm{Li}^{+}, \mathrm{K}^{+}\right.$ ,Rb+ Single Crystals”, J. Kor. Sensors Soc., vol. 12, no. 1, pp. 1-9, 2003.

[6] P. Brinckmann, "CsI(Na) scintillation crystals", Phys. 
Lett., vol. 15, Issue 4, pp. 305, 1965.

[7] O. L. Hsu and C. W. Bates Jr.,"Luminescence phenomena in CsI:Na", J. Lumin., vol. 11, Issues 1-2, pp. 65-74, 1975.

[8] “ROOT User's Guide”, CERN, 2012.

[9] M. Globus, B. Grinyov, and Jong Kyung Kim, Inorganic Scintillators for Modern and Traditional Applications, Institute for Single Crystals, UkraineKharkiv, pp. 38, 2005.

[10] N. Balamurugan, et al., "Growth and character- ization of undoped and thallium doped cesium iodide single crystals", J. Crystal Growth, vol. 286, Issues 2, pp. 294-299, 2006.

[11] "Photomuliplier XP2260”, PHOTONIS, 2006.

[12] E.J. Bosze, et al., "Improving the efficiency of a blue-emitting phosphor by an energy transfer from $\mathrm{Gd}^{3+}$ to $\mathrm{Ce}^{3+}$, J. Lumin., vol. 104, Issues 1, pp. 4754, 2003.

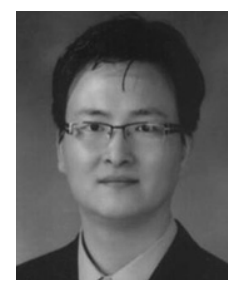

\section{천 종 규 (Jong-Kyu Cheon)}

- 2000년 대구한의대학교 물리학과(이학 사)

- 2002년 경북대학교 물리학과(이학석사)

- 2009년 경북대학교 물리학과(이학박사)

- 2010년 현재 서라벌대학교 방사선과 교수



\section{김 홍 주 (Hong-Joo Kim)}

- 1984년 고려대학교 물리학과(이학사)

- 1986년 고려대학교 물리학과(이학석사)

- 1987년 경북대학교 물리학과(이학박사)

• 1987년 1997년 Luisiana 주립대학교 연구원 및 연구교수

- 1997년 2004년 서울대학교 초빙교수 및 연세대학교 연구교수

- 2004년 현재 경북대학교 물리학과 교 수

\section{김 성 환 (Sunghwan Kim)}

- 1990년 경북대학교 물리학과(이학사)

- 1993년 경북대학교 물리학과(이학석사)

- 2003년 경북대학교 물리학과(이학박사)

- 2010년 현재 청주대학교 방사선학과 교수 